\title{
Towards Universal Quality Health Care through an Independent Accreditation Agency: A Review
}

\author{
Gabriel R. Borlongan, MD, MPM,,,$^{1,2}$ Ma-Ann M. Zarsuelo, RND, MSc, ${ }^{1,3}$ Michael Antonio F. Mendoza, DDM, MA, ${ }^{1,4}$ \\ Ma. Esmeralda C. Silva, MPAf, MSPPM, PhD ${ }^{1,5}$ and Leonardo R. Estacio Jr., MCD, MPH, PhD \\ ${ }^{1}$ University of the Philippines Manila Health Policy Development Hub \\ ${ }^{2}$ Department of Health - Field Implementation and Coordination Team \\ ${ }^{3}$ Institute of Health Policy and Development Studies, National Institutes of Health, University of the Philippines Manila \\ ${ }^{4}$ College of Dentistry, University of the Philippines Manila \\ ${ }^{5}$ College of Public Health, University of the Philippines Manila \\ ${ }^{6}$ College of Arts and Sciences, University of the Philippines Manila
}

\begin{abstract}
Background. Guaranteeing quality of health care services is part of the objectives of Republic Act No. 11223 or the Universal Health Care (UHC) Act of 2019. In assuring that quality services are delivered by health care providers, they must be accredited to participate in the National Health Insurance Program. The UHC Act mandates the Philippine Health Insurance Corporation (PhilHealth) to recognize third party mechanisms as basis of granting incentives for health facilities that deliver services of higher quality. This review aimed to identify lessons and experiences from literature that can be adopted and contextualized in the Philippine setting, for strategic policies on strengthening the national health facility accreditation system.
\end{abstract}

Methods. A systematic review of literature was conducted to generate evidence-based recommendations from discussions on cross country experiences and local government initiatives towards improved accreditation system.

Results. By virtue of the UHC Act, a form of strategic purchasing is further institutionalized through a rating system that incentivizes health facilities that provide better services in terms of quality, efficiency, and equity. It is imperative to consider the country's previous and current gaps and challenges in accreditation and adopt the best practices of other countries, as appropriate to Philippine's local settings. A tool is proposed in creating a national hospital accreditation system using the domains of leadership and governance, financing and sustainability, standards development, program management, and continuing quality improvement.

Conclusion and Recommendations. With the legitimacy of third party accreditation body mandated by the UHC Act, operationalization of the prescribed mechanisms and organizational structure must enjoin all pertinent stakeholders and be supported by sustainable funds and technical assistance by the government.

Key Words: Third Party Accreditation, National Health Insurance, Universal Health Insurance, Universal Health Care, Health Policy

\section{INTRODUCTION}

Quality health care is one of the three aims of Republic Act No. 11223, or the Universal Health Care (UHC) Act. Specifically, the Law ensures that all Filipinos are guaranteed quality health care goods and services, consistent with the provision of equitable access and financial risk protection. ${ }^{1}$

Corresponding author: Gabriel R. Borlongan, MD, MPM Department of Health - Field Implementation and Coordination Team

San Lazaro Compound, Rizal St.,

Santa Cruz, Manila 1003, Philippines

Email: gabrielborlongan@gmail.com
Since the inception of the National Health Insurance Program (NHIP), health services are purchased by the Philippine Health Insurance Corporation (PhilHealth) in behalf of its members and their respective dependent beneficiaries. Hence, PhilHealth pays the rendered services of accredited health care providers that are within 
PhilHealth's covered benefits and for which quality of the service complies to the set standards. This quality of health care provision is assured through the regulatory mechanism of PhilHealth accreditation. Thus, health care facilities should comply with the minimum standards of PhilHealth to be accredited and be able to participate in the NHIP. By virtue of the UHC Act, this form of strategic purchasing is strengthened and instituted further through a rating system that incentivizes the health facilities that provide services at par or better than the established standards in terms of quality, efficiency, and equity. ${ }^{2}$

To assist health policy makers in strengthening the national health facility accreditation system, this review aimed to determine applicable lessons and experiences that can be tailored in the Philippine context. Based on available local literature and official publicly available legislations and administrative issuances from the Department of Health (DOH) and PhilHealth, the current picture of accreditation is depicted in this paper. To deduce evidencebased recommendations on strategic reforms that will structure the institutionalization of health care accreditation system, it is imperative to look at different country profiles, particularly those that share similar socio-economic and geographic profiles. Synthesis of both international and local evidence and the derived lessons were discussed to propose possible arrangements on how accreditation system could transition to, in light of the UHC Act.

\section{METHODS}

A systematic review of literature was conducted to search for evidence in literature pointing to international and local experience on accreditation, focusing on perspectives at the national level. Figure 1 shows the PRISMA diagram of article search. To initiate the scoping, a search through the PUBMED library was conducted in December 2019 using

\section{Identification}

\section{Screening
Eligibility \\ Screening
Eligibility}

2553 records identified through a PUBMED MeSH term search on 'healthcare' AND 'accreditation'
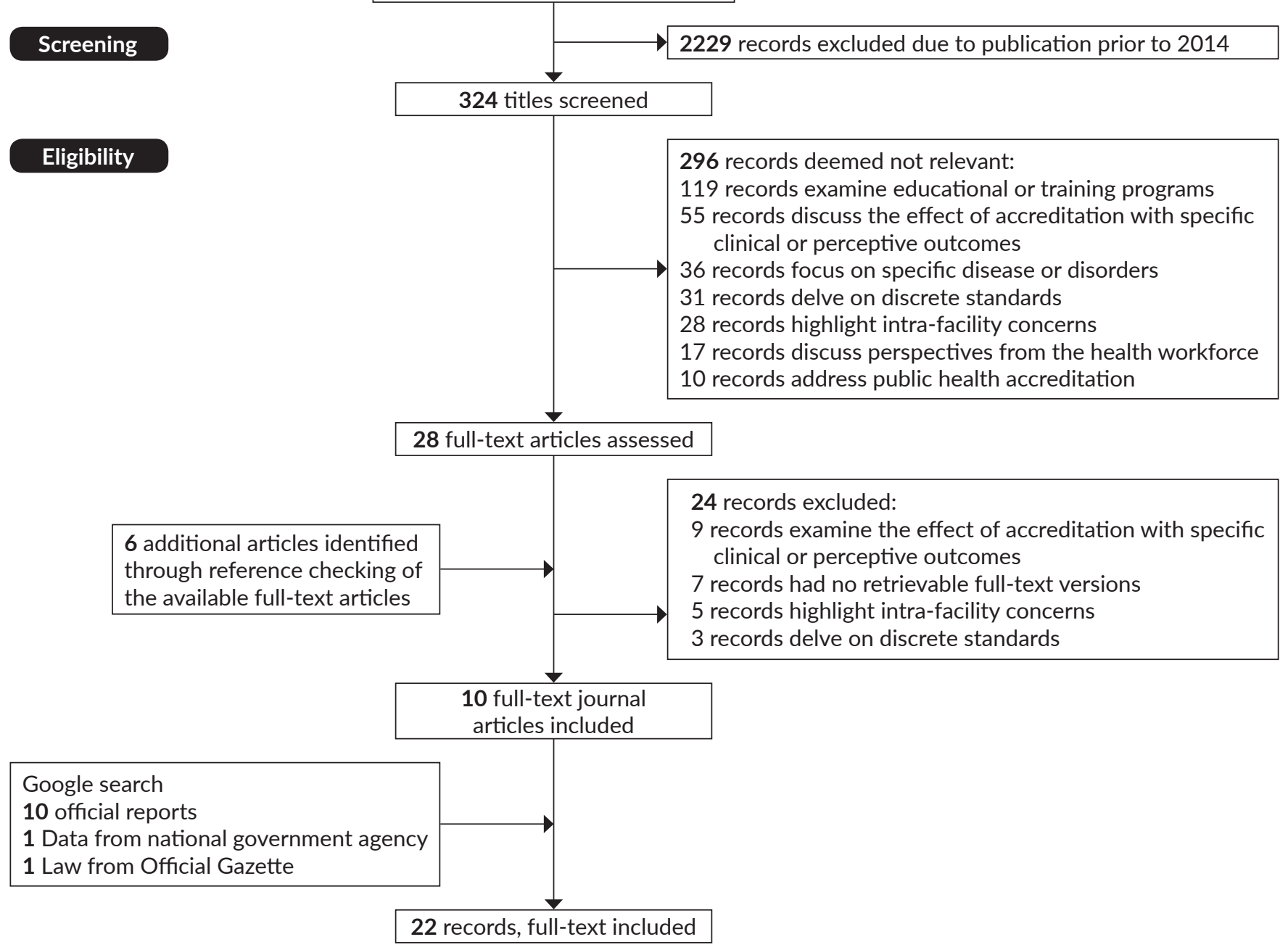

Figure 1. PRISMA diagram of identified records and included studies. 
the MeSH terms "healthcare" and "accreditation," yielding 2,553 articles. To ensure timeliness and applicability to the review and discussion, only records published between January 1, 2014 and December 1, 2019 were included resulting to 324 articles. Titles were screened for relevance with 296 articles excluded if these focus on educational and training programs; the effect of accreditation to clinical or perceptive outcomes; specific set or itemized standards; disease-oriented focus; specific treatment modalities; specific specialties or departments within the hospital; health workforce perspectives; or public health functions. In total, 28 full-text articles were examined to identify pertinent narrative elements and qualitative information. The unavailability of the full-text versions in English of seven articles and the ineligibility of 17 of the remaining articles, resulted to further exploration of reference sources, such as document bibliographies, books, and official reports from websites of national government agencies and nongovernment organizations. This led to 12 additional records, where exception in publication year was granted as the wealth of discussion in its narrative contributed substantially to the discussion. A total of 22 mixed type of full-text records were included in the review.

Lessons from the cited studies were identified, thematically categorized and analyzed to the general elements of third party accreditation, which were then grouped based on discrete similarities as functional components of an ideal national health facility accreditation system. Experiences drawn from the country case studies were examined and compared with the current Philippine health care system landscape, and the reforms ascribed in the UHC Act. From this comparison, recommendations were then summarized for each thematic element.

\section{RESULTS AND DISCUSSION}

\section{Defining Quality}

Quality takes on various identities. The Institute of Medicine, an American non-governmental policy research organization, listed the following as key domains: safety, effectiveness, equity, timeliness or accessbilty, integration of care, patient-centeredness or acceptability, and efficiency. ${ }^{3}$ These facets of health care quality are likewise reflected within the strategic pillars of FOURmula One Plus for Health (F1 Plus for Health), the current medium-term strategic framework of the government of the Philippines for 2017 to 2022. ${ }^{4}$ The UHC Act institutionalizes regulatory reforms that the F1 Plus for Health puts primacy on. Safety is exemplified through the expansion of scope of facilities subjected to licensing, which now includes the stand-alone ambulatory or primary care providers. Effectiveness is assured by mandatory use of clinical pathways where standards are set by the $\mathrm{DOH}$ together with the academe or professional societies. Equity is recognizable primarily from the universal coverage by virtue of citizenship, wherein all Filipinos including migrants abroad are entitled to accessible quality care, subject to membership category. This is further upheld in the long term through the prioritization of geographically isolated and disadvantaged areas through the assistance and support of the National Government. On the other hand, in the immediate time frame, there would be preferential licensing of health facilities with allotment of a certain proportion of beds for basic or ward accommodation. Integration of care is achieved not only through comprehensiveness of services, but also through changing the landscape of service delivery through the development of health care provider networks and province-wide or city-wide health systems. It is also stipulated in the Law that private providers are encouraged to participate. This seeks improved coordination and continuity of care, while concurrently targeting improved coverage and reduced expenditure. ${ }^{1}$

In measuring quality of care, the pioneer model by Donabedian theorizes that changes in the structure of health system inputs such as infrastructure, human resources, medicines and technology, lead to improved processes, snowballing to better health outcomes. These processes at the micro level include diagnosis, treatment, and behavioral change interventions. Meanwhile, health outcomes range from the individual clinical changes to population outcomes, cost containment, and patient satisfaction. ${ }^{5}$ Over the years, more attention is given to the process of health service delivery, particularly the domains of quality interventions. This includes leadership, information, patient and population engagement, regulation and standards, organizational capacity, and models of care. Interventions from discrete categories have to be aligned together considering that improving quality may potentially effect access to and cost of health services. ${ }^{6}$ The confluence of these goals leads to the mode of strategic purchasing, currently being employed in the Philippines, and as legally supported by the Universal Health Care Act. ${ }^{4}$ In the operationalization of the purchasing and procuring of health services and goods, clear delineation of roles must be set to ensure efficiency in health financing.

With the legal mandate in place, complemented by economic instruments, an accreditation system that authorizes providers deemed eligible to participate in the NHIP, may strengthen the assurance of quality in its various domains. This is further rationalized by the current reality on the proportion of government and privately owned health facilities. In 2017, 61\% of PhilHealth-accredited health facilities are under the direct control of either the national government or local government units (LGUs), with a significant proportion under the management of LGUs. Should an incentive basis system and differential payment schemes consider the domains of service quality, efficiency, and equity as metric or criteria, then these domains would be linked to the strategic pillar of financing of the Universal Health Care Act. ${ }^{7,8}$ 


\section{Country Case Studies on Accreditation Systems}

While incentive basis systems have been shown to incentivize high-performing facilities in low-to-middleincome countries (LMICs), accreditation systems behave differently in terms of the body or set of bodies that handles accreditation. ${ }^{9}$ It can be from the government, from insurance companies, or a peer-led organization. Government-led bodies may have the highest form of authority but this may also result in rigidity in the development of standards. ${ }^{10}$ The preferential attention for participation of public providers may lead to questionable objectivity and conflict of interest as the government may soften the standards or surveying for the facilities they own. ${ }^{11}$ This bias manifests more when there is a high proportion of private providers such that standards may not be set too high so that public providers can be accredited, leading to palpable inequalities in perceived quality among the two major groups. ${ }^{10}$

Health insurance companies have the strongest link to incentivization but the risk of under-utilization of services for efficiency gains may undermine the quality assured by the accreditation process. Each insurance company may also have a different set of standards that it will be difficult for providers to maximize their participation in their respective programs. This is more evident in systems with multiple private health insurance companies. A considerable advantage is that the burden of the government in financing the accreditation body is passed on to the insurance company. The insurance company may then pass this on to the facility applying for accreditation. ${ }^{10}$ However, it will still be the government that may have to bear most of the risk in financing, especially in situations where there is a wide government-led national health insurance program. ${ }^{11}$

Lastly, the peer-led model where health or management professionals govern themselves according to quality of care is notable in the sense that professionals set the standards for their professional practice. Disagreements may be minimized as to the professional autonomy being perceived to be affected by models that are external to the professional bodies. ${ }^{10}$ Care must then be taken as this may theoretically heighten the standards beyond what is evidence-based and financially acceptable, especially when there is strong financial incentive for providers to be accredited. ${ }^{11}$

Regardless of the model of the body, accreditation appears to improve quality across all facilities of the health care system regardless of the facility's accreditation status. ${ }^{9}$ Majority of the literature provide evidence supporting the logical link between the organizational change of the facility and the respective outcomes measured. Accredited facilities display organizational change that improves defined outcomes. ${ }^{12} \mathrm{On}$ a larger national scale, paucity in literature is noted for case studies and reports on country experiences among LMICs and Southeast Asian countries on their national accreditation systems. ${ }^{13}$

A cross-sectional study showed that in LMICs, commitment of the national government in terms of policy and financial support were associated with the financial and operational sustainability of the accreditation system. It was suggested that the association could be related to the socioeconomic context of limited resources in terms of technical capability and availability of experts in performing accreditation and financial sustainability of the operations. Financial sustainability is seen to be influenced by government policies, volume of healthcare market, stable funding, incentives for participation of facilities, and continuing quality improvement of the agency itself. ${ }^{14}$

For progressive accreditation, focus should be widened outside individual facilities, looking at the health system as a whole. Government engagement can be stratified by the depth of roles in financing, organizational structure, and decision-making of the accreditation. The accreditation agency must be manned by a pool of competent members with diverse expertise, coming from key involved stakeholders. These include, but are not limited to, patients or civil society organizations, hospital administrators, health professionals of different cadre, the academe, and government representatives. Examining other countries' agency composition, India, Indonesia, and Malaysia have their accreditation agencies independent of the government. The opposite is seen in Thailand which still has government linkages in terms of financing the Healthcare Accreditation Institute. ${ }^{15}$

In Liberia, a government-dependent accreditation system was implemented in 2007, with its initial aim of mapping out its providers of services both in the public and private sectors, from human resources to health facilities. This was beneficial during the initial time frame of implementation as their aims focused on service provision, responsiveness to the stakeholders, and a streamlined management of nongovernment organization (NGO) assistance, of which the country was heavily reliant on. Quality improvement was not a main objective of accreditation at that time, as they were transitioning from a period of democratic unrest. Through government stability, and maturation of their health system, it was recommended that this function be transferred to an autonomous organization. ${ }^{16}$

Zambia, a developing African country, assembled its accreditation program from 1997 to 2000. It was generally successful in setting up their own standards and surveying no more than a hundred hospitals with improved compliance. However, it faced difficulties in establishing legitimacy in authority and fund sufficiency, both influencing programmatic issues on surveyor retention. The notable absence of a linkage of the accreditation system with incentives, one of the enabling drivers, hindered the sustainability for individual facilities and for the whole system. ${ }^{17}$

In Thailand, accreditation had its own foundation from quality improvement programs towards public hospitals under the total quality management framework since 1993. This was later institutionalized in 1999 as the Institute of Hospital Quality Improvement and Accreditation 
under the Health Systems Research Institute. With their own policy of Universal Health Coverage under way in 2001, accreditation was fortified under a mode of strategic purchasing. ${ }^{18}$ The agency had challenges in terms of unclear purpose and expectations, inappropriate technical approach, limited stakeholder involvement, low provider motivation, and poor cooperation between professionals and government bodies. Given the stature of Thailand in its advanced journey to universal health coverage, the country's achievements were attributed to government support in terms of policy endorsement, program acknowledgement and financing, technical support networks, and alignment with other regulating and purchasing mechanisms. ${ }^{17}$

As with Thailand, Brazil had a similar history where accreditation began as a program of the Ministry of Health on quality assurance and improvement in health. From a program, it evolved to a technical committee that developed hospital accreditation standards and more objective guidelines of quality. In contrast with Thailand, a private law entity was created to further refine and apply these standards for their accreditation process. ${ }^{20}$

As for Israel, they have focused on quality in primary care, where licensing and accreditation are considerably more advanced than in hospitals. In-country accreditation system for hospitals is not apparent. To complement this, licensing of hospitals requires accreditation by the Joint Commission International. As of 2017, two-thirds of their hospitals have been accredited. ${ }^{21}$

\section{Synthesis}

The various experiences reflected in the systematic review do not discriminate for or against the socioeconomic status of the countries profiled. There were common themes and recommendations throughout the years. Thematic analysis of the cited literature provided the functional components and individual elements of an ideal national health facility accreditation system. Table 1 presents these recommendations according to thematic groups.

In its ideal form, the national accreditation agency should fulfill the five functional components of leadership and governance, financing and sustainability, standards development, program management, and continuing quality improvement. The agency should have its own metrics of quality in terms of the five components and later aim for accreditation by the international accreditor of accreditation agencies.

Table 1. Recommendations for an ideal national health facility accreditation system as applied locally

$\begin{array}{lll}\text { Functional } & \text { Element } & \text { Recommendations from Review of Literature as applied to local context }\end{array}$

\section{Component/s}

Leadership Legal support

and

Governance
A policy instrument or law must be present to establish the agency's mandate and delineate the roles from the national department or ministry of health and national health insurance agency, if available. ${ }^{14}$ Based on the UHC Law, further guidelines must be formed to explicitly state the mandate and role delineation. While the creation of the Health Technology Assessment Council is defined under the Law, it remains to be seen if another legislative instrument is needed to establish this agency. ${ }^{1}$

Relationship of This may be independent or government dependent as long as there is clear delineation of authority the accreditation and level of independence in internal management of standards development, surveying process, and agency with determining the accreditation of hospitals. ${ }^{14}$

the national The Law's definition of third party accreditation needs to be elaborated as to what it is external to for it government can be interpreted as the health accreditation system as a government entity, a civil society organization, or both. ${ }^{1}$

Relation with Accreditation should be voluntary, but linked to the insurance program, to encourage transparency and hospitals avoid facilities from gaming the system. ${ }^{14,16,18}$

This is currently in place by virtue of the National Health Insurance Act. ${ }^{6}$

Stakeholder Inclusion of each cadre of health workers, representatives from the DOH, PhilHealth, and patient groups or involvement advocates, in the highest decision-making body governing the agency. ${ }^{15,16,18,22}$

As this agency is to be established or explored further, this whole-of-society approach is to be manifested in the operationalization. ${ }^{1}$

Feedbacking of results of the accreditation process to all stakeholders should include disclosure of results to the public. ${ }^{15,16,18}$

The underlying framework of a whole-of-society approach towards UHC is to manifest through its more operational level. ${ }^{1}$

Financing and Sustainable Sustainability financing

As currently practiced, to render the whole accreditation process sustainable, while also minimizing subsidies and possible conflict of interest, fees should be sourced from the hospitals seeking accreditation..$^{0,14,18,22}$

Facilities with proven significant inadequacy to meet structural goals should be given institutional support, by the government or facilitated by the government for donor support. $15,16,18,22$

The UHC Law mandates the national government to provide grants to improve the competitiveness of the public health service delivery system, with priority for underserved and unserved areas. ${ }^{1}$

Alignment of Ensuring that incentives accorded by the National Health Insurance Program is commensurate to the incentives to the expense of hospital-level improvement to attain accreditation. ${ }^{14,15,16,22}$

National Health The section on Evidence-informed Sectoral Policy and Planning of the UHC Law may enable the conduct Insurance Program of health policy and systems research with the availability of health-related data, including financing. ${ }^{1}$ 
Table 1. Recommendations for an ideal national health facility accreditation system as applied locally (continued)

\section{Functional Component/s

Standards Selection of

All domains of quality, should be included, with special attention to non-clinical standards such as of patient Development standard measures experience, staff work life, and governance. ${ }^{15,18}$

As various dimensions of quality manifest, the assessment tool currently being used by PhilHealth must be regularly evaluated together with the rating system to be developed that acknowledges and rewards health facilities that provide better service quality, efficiency, and equity. ${ }^{1}$

Outcome and process indicators should be prioritized over structure indicators but all three kinds of indicators should be included. ${ }^{15,18}$

With the reform on mandatory submission of health-related data, this can be pursued. ${ }^{1}$

To provide objective ratings, a numerical scale should be employed for each indicator, or through a grading system for the whole assessment. ${ }^{14,15,18}$

The rating system that will be established by PhilHealth, as aligned with the current assessment tool for accreditation can be harmonized to implement this. ${ }^{1}$

To provide consistency, parameters and indicators measured by other quality measurement systems and national health programs must be harmonized with the standards to be used by the accreditation system. $15,18,22$ With the direction towards interoperability of health information systems, timely implementation of this process together with health systems and policy research could be aligned. ${ }^{1}$

Standards To dissuade from venturing into provider-centric accreditation that may further widen the information development asymmetry, multiple stakeholders including patient groups or advocates, the academe, and professional process societies must be part of the development of standards..$^{15}$

The underlying framework of a whole-of-society approach towards UHC has to manifest through this more operational level. ${ }^{1}$

Perception of Accreditation standards should be balanced with local context but with an aim to drive facilities to heighten accreditation their compliance to standards..$^{15.16 .17,22}$ standards The existing standards must then be regularly reviewed to enable this drive for competitiveness. ${ }^{1}$

Program Surveyors Selection of surveyors based on professional background so that individuals with attention to detail and Management considerable familiarity to healthcare will not find it difficult surveying. ${ }^{15,16.17,18}$

As the UHC Law does not specify the surveying process, policy instruments in the form of guidelines, after a careful review of the existing practices and supply of surveyors, may be needed to support this recommendation. ${ }^{1}$

Formal certification or training program of surveyors to standardize quality of surveying among different individuals. ${ }^{14,15,17}$

If surveyors are considered as part of the health workforce, this can be included as part of the National Health Human Resource Master Plan to be formulated and implemented by the DOH, together with stakeholders. ${ }^{1}$

Surveying A range of assessment tools from desk review, observation in announced and unannounced visits, and $\begin{array}{ll}\text { practices } & \text { interviews must be employed to balance validity, duration, and thereby cost in conducting the survey. }{ }^{14,15,17,18,19} \\ \text { The protocols on assessment and its validation may need to be further explored in succeeding administrative }\end{array}$ issuance as the UHC Law does not specify this level of detail. ${ }^{1}$

Attention to support and guide the hospitals towards developing and implementing their own quality improvement plans. ${ }^{14,15,17,18,19}$

While not outlined in the UHC Law, this can be incorporated as part of the non-financial matching grants to improve the functionality of province-wide and city-wide health systems. ${ }^{1}$

Duration of validity of accreditation should balance the costs of surveying, while also be frequent enough so that the site will not fall into disinterest before the next survey period. ${ }^{18,19}$

The current multi-year validity of accreditation can be evaluated through economic evaluation by virtue of the health policy and systems researches being pursued. ${ }^{1}$

Continuing Continuing quality Oversight of the accreditation agency by other agencies or evidence of processes that ascribe to continuing Quality improvement of quality improvement of the accreditation agency itself. ${ }^{15}$

Improvement the body itself In identifying the mechanism of accountability through a whole-of-government approach, the establishment of this agency is to be manifested in policies that have not yet been in place in the UHC Law. ${ }^{1}$

Accreditation of Accreditation of the agency by an international organization (e.g., International Society for Quality). ${ }^{15}$

the body itself This aim may manifest as one of the strategic commitments of the agency, once instituted, as this provision is not yet included in the UHC Law. ${ }^{1}$

To be able to lead and govern, its legal mandate for existence and functional extent must be established. To maintain its integrity and demonstrate effective participatory governance, a board or steering committee could oversee its key directions towards the national goals on universal quality health care. Delineation of authority should at the minimum be its development of standards. Their authority over surveyors is crucial. Hence, level of control should only be in ensuring that assessors are certified to pass eligibility criteria and that they do not directly influence facility assessment. Bias could be mitigated through process checks, audits, and multi-stakeholder engagement of various 


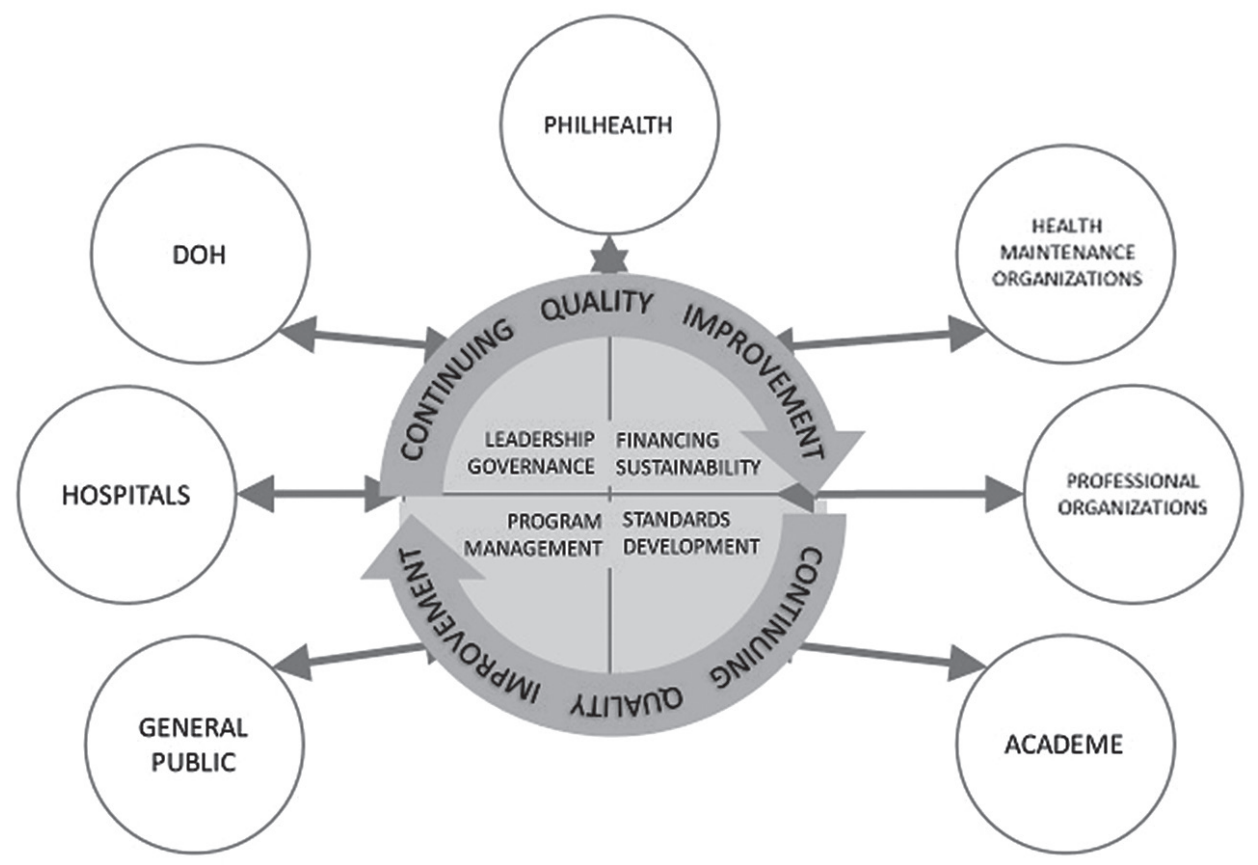

Figure 2. Proposed board or steering committee of the national accreditation agency.

expertise and perspectives, across the government, private, academic, professional, and lay sectors. Figure 2 shows the sectors that will represent the board or steering committee with the five organizational functions of the agency in the middle. The mandates and interests of each stakeholder must be considered, from the mixed regulator-provider nature of the Department of Health and its attached hospitals, to the financial sustainability of privately-owned health facilities.

Standards concurred by the steering committee will pave the way in structuring effective program management, which depends on the quality of surveyors, process of accreditation, and compliance measures. It should be noted that assessment of each standard and associated criteria calls for the specific capacities needed from the surveyors. The standards set must include the structures, processes, and outcome indicators a facility must possess or perform. As health indicators are inextricably associated with different components of the health system, the standards should be designed to reinforce shared accountability among the health facility, the local and the national government, and the private sector. ${ }^{22}$

Sustainable financing must then follow to ensure that the vision set out by the steering committee is attained within the timeframe. The primary goal is to maximize credibility of the accrediting agency while being costeffective. Hence, institutional support from the government is needed particularly at the start-up phase, while funds from other sponsors such as international NGOs could be explored. In controlling the cost of the accreditation which would dictate the fees, cost-effectiveness of the whole operation must be analyzed and monitored. ${ }^{22}$ For example, the national government can initially fund the personnel and administrative expenses of the accrediting agency, while cost of accreditation process such as site visit, administering, and evaluating the facilities shall be shouldered by the applicants. Whichever financing scheme is employed, applicants or the recipients of services, must be informed and commit in their financing role. For example, if user fees will be hailed, subscription fees are borne exclusively by the NHIP, without negatively impacting the quality of services currently offered nor compromising integrity.

To mitigate the risk of high costs in starting up a new agency, financing to sustain the operations of this third party agency requires substantial support from the national government, in addition to the revenues from accreditation fees. ${ }^{16,17}$ It must then grow into a more sustainable model, to insulate itself from conflict of interest with either the purchaser or provider of services; hence, be directed to the recipient of quality healthcare.

The relationships of this accreditation body to its direct clients - the health facilities - must be strengthened through assurance of financial incentives provided by the purchaser or PhilHealth. Its mandate to the public, the endbeneficiary of its activities, could be strengthened through marketing and highlighting client satisfaction or experience as one of its quality indicators. While still looking for the accreditation body to fully manifest its functional capacity to develop standards and survey all applicant health facilities, an option in the interim transition period is to use existing resources. This option is illustrated in Figure 3, showing the relationships of the third party accreditation agency with government agencies. The Department of Health provides administrative control over DOH Centers for Health Development (CHDs). The CHDs receive training and certification in surveying from the accreditation agency. 
Communicating Results

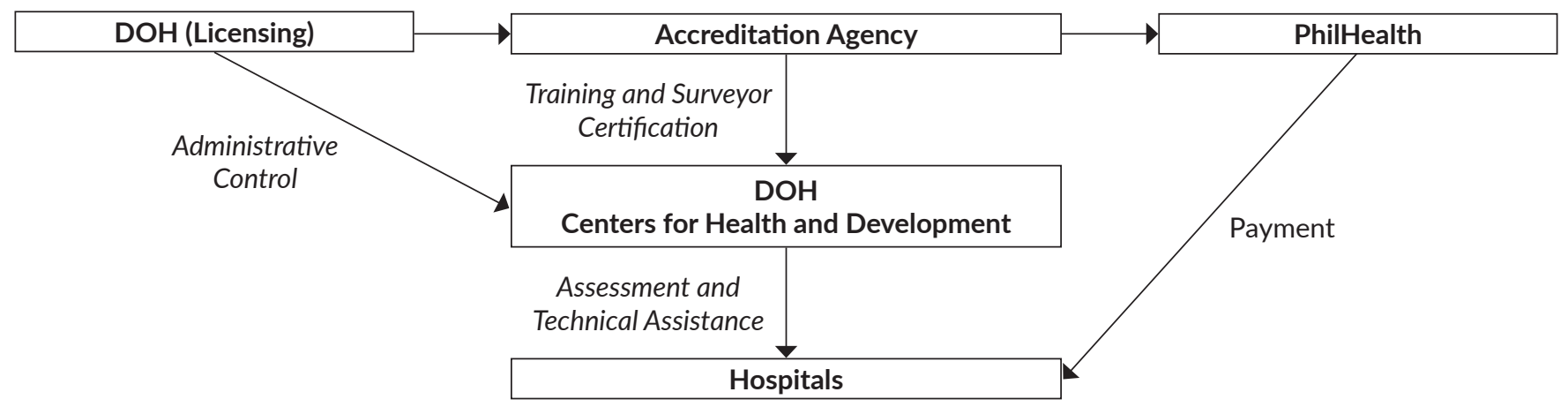

Figure 3. Relationship diagram of the accreditation agency with key government actors during the interim period.

The CHDs then assess and consequently provide technical assistance, as part of their institutional mandate. CHDs shall then feedback their findings to the accreditation agency, in which the latter shall communicate these results to PhilHealth. Based on parameters and standards of PhilHealth, PhilHealth shall then pay hospitals when eligible.

\section{CONCLUSION AND RECOMMENDATIONS}

The current situation shows that the purchaser of services also gatekeeps healthcare providers from participating in the National Health Insurance Program. With the experience of hospitals in quality assurance programs for almost a decade, it is a ripe time to venture to a new system of accreditation with the entry of a third party accreditation agency. As the UHC Law has already provided the necessary legislative support and direction, this must be committed to by a formulation of a long-term plan with initial funding from the strategic purchaser, PhilHealth. The plan should include the improvement of standards over time to become more comprehensive and relevant to the six domains of quality. Meanwhile, technical assistance and capacity building particularly of the surveyors could be sought from the Department of Health, and internationally established accrediting agencies. The medium to long-term goals should then be sustainably followed through with transitional strategies of support. By enacting this, Universal Health Care will be progressively realized and a more defined delineation of primary objectives to the major health care system agencies is also realized to attain access, quality, and financial risk protection on health services.

As the study utilized a systematic review of literature to develop its proposal, it is imperative to run the transitory proposal towards an independent accreditation body through a series of consultations with relevant key officials on the policy sector, the academe, health care providers, facility administrators, and patient representatives. These consultations could unravel the values each sectoral representative put premium on. This will further refine the proposal in its most feasible and implementable form.
A formal evaluation of the current accreditation system based on its mandates and the earlier mentioned functional components will bring more grounded evidence on the gaps that have to be addressed. The soundness of the plan with a realistic budgetary request can then be confidently lobbied to the national government or through other sources.

Functions in terms of the end goals of a system improved accessibility, quality, and affordability, are currently being delineated at the national level. A possible field to explore is health regulation by the decentralized levels of the Philippine health care system. This will guide in determining the capacities needed for local governments to adequately assure quality health services among facilities within their jurisdiction. Examining this may contribute to the effective transition of local health systems to province-wide and citywide health systems.

\section{Statement of Authorship}

All authors participated in data collection and analysis, and approved the final version submitted.

\section{Author Disclosure}

Dr. Borlongan declares his engagement with the UPM $\mathrm{HPDH}$ during the project duration only. $\mathrm{He}$ is currently working as a Medical Officer - III, specifically as Technical Secretariat to the Universal Health Care Integration Sites, under the Department of Health.

\section{Funding Source} HPSR.

This project was funded by the DOST DOH AHEAD-

\section{REFERENCES}

1. Republic Act 11223. An Act Instituting Universal Health Care for All Filipinos, Prescribing Reforms in the Health Care System, and Appropriating Funds Therefore.

2. Mathauer I, Dale E, Meessen B. Strategic purchasing for Universal Health Coverage: key policy issues and questions. A summary from expert and practitioners' discussions. Geneva, Switzerland: World Health Organization; 2018. 
3. Institute of Medicine. Crossing the Quality Chasm: A New Health System for the 21st Century. Washington, DC: The National Academies Press; 2001. doi: 10.17226/10027.

4. World Health Organization, Organisation for Economic Co-operation and Development, and The World Bank. Delivering quality health services: a global imperative for universal health coverage. Geneva, Switzerland: World Health Organization; 2018.

5. Li Z, Wang B, Zhou Y. The current situation and analysis of medical and health service regulation in China. Paris, France: Organisation for Economic Co-operation and Development; 2007.

6. Philippine Health Insurance Corporation. Stats \& Charts. Pasig City, Philippines: Philippine Health Insurance Corporation. 2019.

7. Donabedian A. The evaluation of medical care programs. Bull N Y Acad Med. 1968 Feb; 44(2):117-24.

8. World Health Organization. Quality of care: a process for making strategic choices in health systems. Geneva, Switzerland: WHO Press; 2006.

9. Alkhenizan A, Shaw C. Impact of accreditation on the quality of healthcare services: a systematic review of the literature. Ann Saudi Med. 2011 Jul-Aug; 31(4):407-16. doi: 10.4103/0256-4947.83204.

10. Nandraj S, Khot A. Accreditation system for health facilities: challenges and opportunities. Economic and Political Weekly. 2003 Dec; 38(50):5251-5.

11. Tulchinsky TH, Varavikova EA. Health technology, quality, law and ethics. The New Public Health. 2014; 771-819. doi: 10.1016/B978-012-415766-8.00015-X.

12. Pomey MP, Contandriopoulos AP, François P, Bertrand D. Accreditation: a tool for organizational change in hospitals? Int $\mathrm{J}$ Health Care Qual Assur Inc Leadersh Health Serv. 2004; 17(2-3): 113-24. doi: 10.1108/09526860410532757.

13. Hort K. Approaches to regulating the quality of hospital services in low- and middle-income countries with mixed health systems: a review of their effectiveness, context of operation and feasibility. Melbourne, Australia: Nossal Institute for Global Health; University of Melbourne; 2013.
14. Braithwaite J, Shaw CD, Moldovan M, Greenfield D, Hinchcliff $\mathrm{R}$, Mumford V, et al. Comparison of health service accreditation programs in low- and middle-income countries with those in higher income countries: a cross-sectional study. Int J Qual Health Care. 2012 Dec; 24(6):568-577. doi:10.1093/intqhe/mzs064.

15. Smits H, Supachutikul A, Mate KS. Hospital accreditation: lessons from low- and middle-income countries. Global Health. 2014 Sep; 10:65. doi:10.1186/s12992-014-0065-9.

16. Cleveland EC, Dahn BT, Lincoln TM, Safer M, Podesta M, Bradley E. Introducing health facility accreditation in Liberia. Glob Public Health. 2011; 6(3):271-82. doi:10.1080/17441692.2010.489052.

17. Bukonda N, Tavrow P, Abdallah H, Hoffner K, Tembo J. Implementing a national hospital accreditation program: the Zambian experience. Int J Qual Health Care. 2002 Dec;14 Suppl 1:7-16. doi: 10.1093/ intqhe/14.suppl_1.7.

18. Mate KS, Rooney AL, Supachutikul A, Gyani G. Accreditation as a path to achieving universal quality health coverage. Global Health. 2014 Oct; 10:68. doi:10.1186/s12992-014-0068-6.

19. Sriratanaban J. Accreditation as a Regulatory Tool and QA: Learning from the Asia Experience. Thailand: Chulalongkorn University; 2004.

20. Correa JE, Turrioni JB, de Paiva AP, de Carvalho Paes V, Balestrassi PP, Papandrea PJ, et al. The Influence of Accreditation on the Sustainability of Organizations with the Brazilian Accreditation Methodology. J Healthc Eng. 2018 Jan; 2018:1393585. doi: 10.1155/2018/1393585.

21. Clarfield AM, Manor O, Nun GB, Shvarts S, Azzam ZS, Afek A, et al. Health and health care in Israel: an introduction. Lancet. 2017 Jun; 389(10088):2503-2513. doi:10.1016/s0140-6736(17)30636-0.

22. Public Health Accreditation Board. Final recommendations for a voluntary national accreditation program for state and local public health departments. September 2006. 